Article

\title{
Expansion of Necrosis Depending on Hybrid Motor-Driven Motility of Aeromonas hydrophila in a Murine Wound Infection Model
}

\author{
Kohei Yamazaki $^{1}$ (D), Takashige Kashimoto ${ }^{1, *}$, Ayuha Niwano ${ }^{1}$, Moeko Yamasaki ${ }^{1}$, Mayu Nomura ${ }^{1}$, \\ Yukihiro Akeda ${ }^{2}$ and Shunji Ueno ${ }^{1}$
}

1 Laboratory of Veterinary Public Health, School of Veterinary Medicine, Kitasato University, 23-35-1, Higashi, Towada Aomori 034-8628, Japan; kyamazak@vmas.kitasato-u.ac.jp (K.Y.); twd_ayu@yahoo.co.jp (A.N.); moekoyama5@biken.osaka-u.ac.jp (M.Y.); vm15101n@st.kitasato-u.ac.jp (M.N.); ueno@vmas.kitasato-u.ac.jp (S.U.)

2 Division of Infection Control and Prevention, Osaka University Hospital, 2-2, Yamadaoka, Suita, Osaka 565-0871, Japan; akeda@biken.osaka-u.ac.jp

* Correspondence: kashimot@vmas.kitasato-u.ac.jp; Tel.: +81-176-23-4371 (ext. 443)

Citation: Yamazaki, K.; Kashimoto, T.; Niwano, A.; Yamasaki, M.; Nomura, M.; Akeda, Y.; Ueno, S. Expansion of Necrosis Depending on Hybrid MotorDriven Motility of Aeromonas hydrophila in a Murine Wound Infection Model. Microorganisms 2021, 9, 10. https://dx. doi.org/10.3390/microorganisms 901 0010

Received: 4 November 2020 Accepted: 18 December 2020 Published: 22 December 2020

Publisher's Note: MDPI stays neutral with regard to jurisdictional claims in published maps and institutional affiliations.

Copyright: () 2020 by the authors. Licensee MDPI, Basel, Switzerland. This article is an open access article distributed under the terms and conditions of the Creative Commons Attribution (CC BY) license (https: / / creativecommons.org/ licenses/by/4.0/).

\begin{abstract}
The gram-negative bacterium Aeromonas hydrophila is a cause of fulminant and lethal necrotizing soft tissue infections (NSTIs). Suppressing the rapid proliferation of the pathogen and expansion of the necrosis caused in the host is an important issue in clinical practice, but the pathogenic mechanism for the rapid aggravation has not been clarified. In this study, we characterized the function of two types of motor stators in A. hydrophila and explored the role of motility during wound infection. In vitro analysis showed that the motility was reliably maintained while being complemented by the stators. We created a non-motile strain that lacked genes encoding two types of motor stators and analyzed the role of motility in a murine wound infection model. Examination of the bacterial burden in the local infection site and systemic circulation revealed that motility was not essential for the proliferation of $A$. hydrophila in the host. However, the extent of necrosis at the lesions was lower, and survival times were prolonged in mice infected with the non-motile strain compared with mice infected with the parent strain. These results provide evidence that the rapid expansion of necrosis and the progression to death within a short time period is dependent on the motility of A. hydrophila.
\end{abstract}

Keywords: Aeromonas hydrophila; necrotic soft tissue infection; motility; flagellum

\section{Introduction}

Aeromonas hydrophila is a rod-shaped, motile, and gram-negative bacterium that is found in wastewater, sewage, and food [1-3]. It is pathogenic to fishes, amphibians, reptiles, and mammals [1-8]. Wound infection of $A$. hydrophila in humans is second most frequent after oral infection and associated with traumatic events and burns and scalds related to water and soil [1-3,9]. Most cases of $A$. hydrophila wound infection occur in healthy people $[1,10]$. In particular, Aeromonas sp. wound infection is reported following natural disasters, such as the tsunami and hurricane [11,12]. The wound infections due to $A$. hydrophila can progress to necrotizing soft tissue infection (NSTI) [7,8]. Necrotizing fasciitis (NF) is the most serious presentation of NSTI, an aggressive subcutaneous infection that spreads along the superficial fascia, which comprises the skin and underlying muscles, and its rapid dissemination can result in more severe disease manifestations such as sepsis [8-10,13,14].

Multiple factors including adhesins, hemolysin, aerolysin, nuclease, proteases, and type VI secretion system effectors are known to be involved in the pathogenesis in $A$. $h y$ drophila infections [1-8]. Ponnusamy et al. and Fernández-Bravo et al. showed that A. hydrophila exotoxin A (ExoA), which has ADP ribosyl transferase activity and targets 
eukaryotic elongation factor-2, is a crucial factor in NF and destruction of the local tissue barrier $[7,15]$. However, the mechanisms involved in the rapid expansion of the necrosis and the progression to sepsis have not been clarified. Since the bacterial pathogens cause significant pathology in hosts for the colonization and proliferation, it is important to identify the mechanisms responsible for the high adaptability and proliferation ability of the pathogens in the host.

Bacterial motility is swimming activity in a liquid environment by rotating the polar and lateral flagella, and this motility enables bacteria to leave unfavorable environments for more suitable ones [16-20]. The flagellin that is a subunit protein of the flagellum is known as a major target as an $\mathrm{H}$-antigen for recognition by the host cells through the toll-like receptor [21]. In addition, it was reported that flagellar-based motility is necessary for $A$. hydrophila adhesion during infection $[22,23]$. Thus, the flagellum and the flagellarbased motility is essential for the pathogenesis of $A$. hydrophila infection. However, the significance of the flagella-mediated movement inside the host body has not been studied. To rotate flagella, the flagellar motor is powered by ion gradients [16-19,24]. Stators of the motor are the transmembrane ion channel that conducts cations such as protons $(\mathrm{H}+)$ or sodium ions (Na+). The MotA/MotB complex is well studied in Escherichia coli and Salmonella and acts as the stator, as the channel across the cytoplasmic membrane converts $\mathrm{H}+$ influx into torque by interaction with the rotor [16-19,24]. The PomA/PomB complex is a Na+-coupled stator unit generally possessed by Vibrio species, which live in seawater and brackish water [18,19,25-28]. A. hydrophila has two or more sets of motor stator proteins [29]. Since this pathogen lives in water environments with various sodium concentrations, the stators are required for adaptation and active motility. Our genome analysis revealed that RIMD111065, which is clinically isolated from patient blood, possessed two types of genes encoding MotA/MotB and PomA/PomB. These facts indicate that adaptable motor stators and motility might provide a survival advantage and could be involved in pathogenicity during the infection.

In this study, we showed that the two types of motor stators of $A$. hydrophila share homology with motor stators in other bacteria and complemented each stator in motility. Further, we employed murine infection models to investigate the pathogenesis during $A$. hydrophila infection. Here, we report that the motility of $A$. hydrophila is essential for the development of necrosis with fatal outcomes.

\section{Materials and Methods}

\subsection{Bacteria}

A. hydrophila clinical isolated strain RIMD111065 with spontaneous rifampicin resistance was cultured aerobically in Luria-Bertani $(1 \% \mathrm{NaCl}, 1 \%$ tryptone, and $0.5 \%$ yeast extract) (LB) broth or on LB agar at $37^{\circ} \mathrm{C}$. When required, the medium was supplemented with chloramphenicol $(5 \mu \mathrm{g} / \mathrm{mL})$ for $A$. hydrophila to maintain the pACYC plasmid. $\Delta m o t X$ is a mutant strain used as a positive control for motility [6].

\subsection{Bioinformatics}

Genome sequences were obtained from NCBI genome database (https:/ / www.ncbi. nlm.nih.gov/genome/) and KEGG database (https://www.genome.jp/kegg/). The genome sequences of the reference strains used in this study have been deposited under the GenBank accession numbers: CP000462 (Aeromonas hydrophila ATCC 7966), LYXO01000024 (Aeromonas piscicola AH-3), U00096 (Escherichia coli K12), AE006468 (Salmonella enterica subsp. enterica serovar Typhimurium LT2), CP000626 (Vibrio cholerae O395), AE016795 (Vibrio vulnificus CMCP6), and AE014300 (Shewanella oneidensis MR-1). Accession number of the genome of Aeromonas hydrophila RIMD111065 is AP024234. Amino acid sequences were inspected by using the BLASTP network service at the NCBI and PRALINE [30]. 


\subsection{Mutants Construction and Complementation}

The $\operatorname{mot} A / \operatorname{mot} B$ (hereafter $\operatorname{mot} A B$ ) and pom $A /$ pomB (hereafter pom $A B$ ) deletion mutants were constructed by the same method for the mutant construction of Vibrio vulnificus [31]. Briefly, the mot $A B$ gene and the pom $A B$ gene were amplified and cloned into the suicide vector pYAK1, retaining sacB. pYAK1-mot $A B \mathrm{KO}$ and pYAK1-pom $A B \mathrm{KO}$ were introduced into $A$. hydrophila RIMD111065. The bacteria retaining pYAK1-mot $A B$ KO or pYAK1-pom $A B$ $\mathrm{KO}$ was cultured in LB broth containing $20 \%$ sucrose following the standard sacB-assisted allelic exchange method. Mutants were confirmed by PCR to detect expected changes in size at the mot $A B$ locus or the pom $A B$ locus. pYAK1-pom $A B \mathrm{KO}$ were introduced into the $\triangle m o t A B$ and also constructed the knockout strain $\triangle m o t A B / p o m A B$. The $\triangle m o t A B$, the $\triangle$ pom $A B$, and $\triangle \operatorname{mot} A B / \operatorname{pom} A B$ were complemented with the full-length $\operatorname{mot} A B, \operatorname{pom} A B$, and $\operatorname{mot} A B / \operatorname{pom} A B$ gene carried by pACYC. The complementation strain pmot $A B$, ppom $A B$, and pmot $A B /$ pom $A B$ were cultured in LB containing $5 \mu \mathrm{g} / \mathrm{mL}$ chloramphenicol.

\subsection{Cytotoxicity Assay}

Cytotoxicities against HeLa cells $(n=6 /$ group, MOI $=10)$ were determined by measuring the activity of lactate dehydrogenase (LDH) released from damaged cells at $2 \mathrm{~h}$ post-infection using a cytotoxicity assay kit (Cyto Tox 96; Promega KK, Tokyo, Japan).

\subsection{Motility Assay}

A. hydrophila was grown in LB medium with agitation $(163 \mathrm{rpm})$ at $37^{\circ} \mathrm{C}$. Overnight cultures $(100 \mu \mathrm{L})$ were inoculated into $2 \mathrm{~mL}$ of fresh LB medium and incubated for $12 \mathrm{~h}$. Bacterial suspensions were inoculated with a sterile toothpick on LB containing $0.25 \%$ agar. Plates were incubated at $37^{\circ} \mathrm{C}$ for $24 \mathrm{~h}$. Motility was assessed by examining the migration of bacteria through the agar from the inoculation site.

\subsection{Mice}

Five-week-old female C57BL/ 6 mice were purchased from Charles River Laboratories Japan (Atsugi, Japan), bred and maintained under specific pathogen-free conditions at Kitasato University, and used for all experiments in our study.

\subsection{Histopathological examination}

A. hydrophila WT and $\triangle m o t A B / p o m A B$ were grown in LB medium with agitation $(163 \mathrm{rpm})$ at $37^{\circ} \mathrm{C}$. Overnight cultures $(100 \mu \mathrm{L})$ were inoculated into $2 \mathrm{~mL}$ of fresh LB medium and incubated for $12 \mathrm{~h}$. Bacteria were harvested, washed with PBS (pH 7.2) containing $0.1 \%$ gelatin, and resuspended in fresh LB medium. Then, PBS or $10^{7} \mathrm{CFU} /$ mouse were subcutaneously inoculated in mice ( $n=6 /$ group). Infected mice were sacrificed at $12 \mathrm{~h}$ post-infection. Right caudal thighs were collected as the inoculation site, demineralized by immersing them in buffer solution containing $0.2 \mathrm{M}$ EDTA- $4 \mathrm{Na}$ and $1 \%$ formalin for 1 week, fixed in $10 \%$ buffered formalin for 1 day, embedded in paraffin, sliced into $2-\mu \mathrm{m}$ sections, and stained with Hematoxylin-eosin. Image acquisition of the soft tissues was performed using an inverted microscope (DM2500/Leica Microsystems, Tokyo, Japan) equipped with $10 \times / 0.40$ objective lenses.

\subsection{Evaluation of Biomarkers}

A. hydrophila WT and $\triangle m o t A B /$ pom $A B$ were grown in LB medium with agitation $(163 \mathrm{rpm})$ at $37^{\circ} \mathrm{C}$. Overnight cultures $(100 \mu \mathrm{L})$ were inoculated into $2 \mathrm{~mL}$ of fresh LB medium and incubated for $12 \mathrm{~h}$. Bacteria were harvested, washed with PBS (pH 7.2) containing $0.1 \%$ gelatin, and resuspended in fresh LB medium. Then, PBS or $10^{7} \mathrm{CFU} /$ mouse were subcutaneously inoculated in mice ( $n=6$ /group). Infected mice were sacrificed at $9 \mathrm{~h}$ post-infection. Whole-blood samples were collected in a syringe by cardiac puncture after infection and centrifuged at $1200 \times g$ for $30 \mathrm{~min}$, and sera were collected. Serum LDH, creatine kinase (CK), and aspartate aminotransferase (AST) concentrations were evaluated using Dimension EXL with the LM Integrated Chemistry System (Siemens, Tokyo, Japan). 


\subsection{Bacterial Counts in Muscles and Spleen}

A. hydrophila WT and $\triangle m o t A B / p o m A B$ were grown in LB medium with agitation $(163 \mathrm{rpm})$ at $37^{\circ} \mathrm{C}$. Overnight cultures $(100 \mu \mathrm{L})$ were inoculated into $2 \mathrm{~mL}$ of fresh LB medium and incubated for $12 \mathrm{~h}$. Bacteria were harvested, washed with PBS (pH 7.2) containing $0.1 \%$ gelatin, and resuspended in fresh LB medium. Then, $10^{7} \mathrm{CFU} /$ mouse were subcutaneously inoculated in mice ( $n=6 /$ group). Infected mice were sacrificed at $12 \mathrm{~h}$ post-infection. The muscles beneath the inoculation site and spleen were collected, suspended in cold PBS containing $0.1 \%$ gelatin, homogenized for $5 \mathrm{~s}$ with a lab mixer IKA EUROSTAR digital (IKA Werke, Germany; $1300 \mathrm{rpm}$ ), and centrifuged at $800 \mathrm{rpm}$ for $5 \mathrm{~min}$. The supernatants were plated at 10-fold serial dilutions in duplicate on LB agar containing $50 \mu \mathrm{g} / \mathrm{mL}$ rifampicin and incubated for $12 \mathrm{~h}$ at $37^{\circ} \mathrm{C}$. A . hydrophila colonies were counted, and bacterial burden was determined by calculating the number of $\mathrm{CFU} / \mathrm{g}$.

\subsection{Mortality Rate}

A. hydrophila WT and $\triangle m o t A B / p o m A B$ were grown in LB medium with agitation $(163 \mathrm{rpm})$ at $37^{\circ} \mathrm{C}$. Overnight cultures $(100 \mu \mathrm{L})$ were inoculated into $2 \mathrm{~mL}$ of fresh LB medium and incubated for $12 \mathrm{~h}$. Bacteria were harvested, washed with PBS ( $\mathrm{pH} 7.2$ ) containing $0.1 \%$ gelatin, and resuspended in fresh LB medium. Then, $10^{7} \mathrm{CFU} /$ mouse were subcutaneously inoculated in mice ( $n=6$ /group). Infected mice were monitored every hour for a maximum of $72 \mathrm{~h}$. Mice were euthanized by inhalation of sevoflurane when exhibit hypothermia and/or are lying.

\subsection{Statistical Analysis}

Statistical analysis was performed using GraphPad Prism (GraphPad Software, CA, USA). Statistical differences between the two groups were analyzed using the MannWhitney $U$ test. Survival curves were analyzed using the log-rank test. A $p$ value less than 0.05 was considered significant, and significance values are indicated as follow: ns, not significant, $p>0.05 ;{ }^{*}, p<0.05 ;{ }^{* *}, p<0.01 ;{ }^{* * *}, p<0.001$.

\section{Results}

A. hydrophila is known to possess two or more flagellar stators. Wilhelms et al. reported that two sodium-driven motor stators are involved in flagellar rotation of $A$. $h y-$ drophila [29]. The amino acid sequences of the two stators, MotAB and pomAB, of $A$. hydrophila RIMD111065 were identical to those of A. hydrophila ATCC7966 (Table 1, Figures S1-S4). This indicates that the stators are conserved in A. hydrophila strains. Although the sequence homology of MotAB of A. hydrophila RIMD111065 was low compared to those of E. coli and Salmonella Typhimurium, residues for interaction with the rotor component FliG and torque generation were conserved (Table 1, Figures S1 and S2) [18,19,24]. Additionally, the homologies of MotAB of A. hydrophila were highest to MotAB of Shewanella oneidensis MR-1, which has been reported to function as a proton channel (Table 1, Figures S1-S4) [32,33]. PomA and PomB of A. hydrophila RIMD111065 had sequence homologies close to those of Vibrio species and S. oneidensis and had essential residues for functioning (Table 1, Figures S3 and S4) [25-28,32-35]. To determine whether the proteins play a role in motility, we created knockout strains $\triangle \operatorname{mot} A B, \triangle \operatorname{pom} A B, \triangle \operatorname{mot} A B / \operatorname{pom} A B$, and their complemented strains. As assessed by light microscopy, WT, $\triangle$ mot $A B$, and $\triangle p o m A B$ cells displayed swimming in LB medium. Motility assay with soft agar plate showed that the motility of $\triangle$ mot $A B$ and $\triangle p o m A B$ were similar to that of WT, whereas that of $\triangle m o t A B /$ pom $A B$ was lacking motility, similar to non-motile strain $\triangle m o t X$ (Figure 1). In addition, motility of $\triangle \operatorname{mot} A B / \operatorname{pom} A B$ was restored by complementing either mot $A B$ or pom $A B$ (Figure 1). Accordingly, these results show that the two types of motor stator of A. hydrophila are individually sufficient to drive flagella rotation and can complement each other in motility. These results showed that both MotAB and PomAB function for motility. 
Table 1. The homology scores and key residues of stator proteins in RIMD111065 and others.

\begin{tabular}{|c|c|c|c|c|c|c|c|c|c|c|}
\hline Protein & Organism & Strain & Length & E Value & Identities & Positives & $\begin{array}{c}\text { Interaction } \\
\text { with FliG }\end{array}$ & $\begin{array}{c}\text { Ion } \\
\text { Channel Pore }\end{array}$ & Ion Binding & $\begin{array}{c}\text { Torque } \\
\text { Generation }\end{array}$ \\
\hline \multirow[t]{5}{*}{ MotA } & A. hydrophila & RIMD111065 & 252 & - & - & - & Arg86 and Glu94 & - & - & Pro150 and Pro199 \\
\hline & A. hydrophila & ATCC7966 & 252 & $0.00 \mathrm{E}+00$ & $252 / 252(100 \%)$ & $252 / 252(100 \%)$ & Arg86 and Glu94 & - & - & Pro150 and Pro199 \\
\hline & E. coli & K12 & 295 & $4.00 \mathrm{E}-16$ & $55 / 210(26 \%)$ & $93 / 210(44 \%)$ & Arg90 and Glu98 & Met206 & Tyr217 & Pro173 and Pro222 \\
\hline & S. typhimurium & LT2 & 295 & $3.00 \mathrm{E}-17$ & $59 / 211(28 \%)$ & $96 / 211(45 \%)$ & Arg90 and Glu98 & Met206 & Tyr217 & Pro173 and Pro222 \\
\hline & S. oneidensis & MR-1 & 243 & $3.00 \mathrm{E}-134$ & $174 / 242(72 \%)$ & $207 / 242(85 \%)$ & Arg86 and Glu94 & - & - & Pro150 and Pro199 \\
\hline \multirow{5}{*}{ MotB } & A. hydrophila & RIMD111065 & 291 & - & - & - & Asp21 & Ala29 & Asp21 & \\
\hline & A. piscicola & AH-3 & 291 & 0 & $280 / 291(96 \%)$ & $285 / 291(97 \%)$ & Asp21 & Ala29 & Asp21 & \\
\hline & E. coli & $\mathrm{K} 12$ & 308 & $3.00 \mathrm{E}-16$ & $73 / 296(25 \%)$ & $135 / 296(45 \%)$ & Asp32 & Ala39 & Asp32 & \\
\hline & S. typhimurium & LT2 & 309 & $3.00 \mathrm{E}-15$ & $72 / 293(25 \%)$ & $124 / 293(42 \%)$ & Asp33 & Ala40 & Asp33 & \\
\hline & S. oneidensis & MR-1 & 275 & $1.00 \mathrm{E}-95$ & $133 / 289(46 \%)$ & $196 / 289(67 \%)$ & Asp21 & Ala28 & Asp21 & \\
\hline \multirow[t]{5}{*}{ PomA } & A. hydrophila & RIMD111065 & 252 & - & - & - & Arg88 and Glu96 & Leu183 & Asn194 & Pro151 and Pro199 \\
\hline & A. hydrophila & ATCC7966 & 252 & 0 & $252 / 252(100 \%)$ & $252 / 252(100 \%)$ & Arg88 and Glu96 & Leu183 & Asn194 & Pro151 and Pro199 \\
\hline & A. piscicola & AH-3 & 245 & $8 \mathrm{E}-35$ & $69 / 241(29 \%)$ & $127 / 241(52 \%)$ & Arg85 and Glu93 & - & Asn193 & pro150 and pro198 \\
\hline & V. cholerae & O395 & 254 & $1.00 \mathrm{E}-116$ & $164 / 247(66 \%)$ & $199 / 247(80 \%)$ & Arg88 and Glu96 & Leu183 & Asn194 & Pro151 and Pro199 \\
\hline & V. vulnificus & СMCP6 & 253 & $3.00 \mathrm{E}-122$ & $163 / 247(66 \%)$ & $200 / 247(80 \%)$ & Arg88 and Glu96 & Leu183 & Asn194 & Pro151 and Pro199 \\
\hline \multirow[t]{6}{*}{ PomB } & A. hydrophila & RIMD111065 & 299 & - & - & - & Asp20 & Cys27 & Asp20 & Phe18 \\
\hline & A. hydrophila & ATCC7966 & 299 & 0 & $299 / 299(100 \%)$ & $299 / 299(100 \%)$ & Asp20 & Cys27 & Asp20 & Phe18 \\
\hline & A. piscicola & AH-3 & 303 & $2 \mathrm{E}-22$ & $70 / 305(23 \%)$ & $124 / 305(40 \%)$ & Asp24 & - & Asp24 & - \\
\hline & V. cholerae & $\mathrm{O} 395$ & 318 & $1.00 \mathrm{E}-134$ & $182 / 302(60 \%)$ & $231 / 302(76 \%)$ & Asp23 & Cys30 & Asp23 & Phe21 \\
\hline & V. vulnificus & СМСP6 & 318 & $4.00 \mathrm{E}-137$ & $187 / 308(61 \%)$ & $234 / 308(75 \%)$ & Asp24 & Cys31 & Asp24 & Phe22 \\
\hline & S. oneidensis & MR-1 & 308 & $9.00 \mathrm{E}-132$ & $182 / 302(60 \%)$ & $222 / 302(73 \%)$ & Asp20 & Cys27 & Asp20 & Phe18 \\
\hline
\end{tabular}




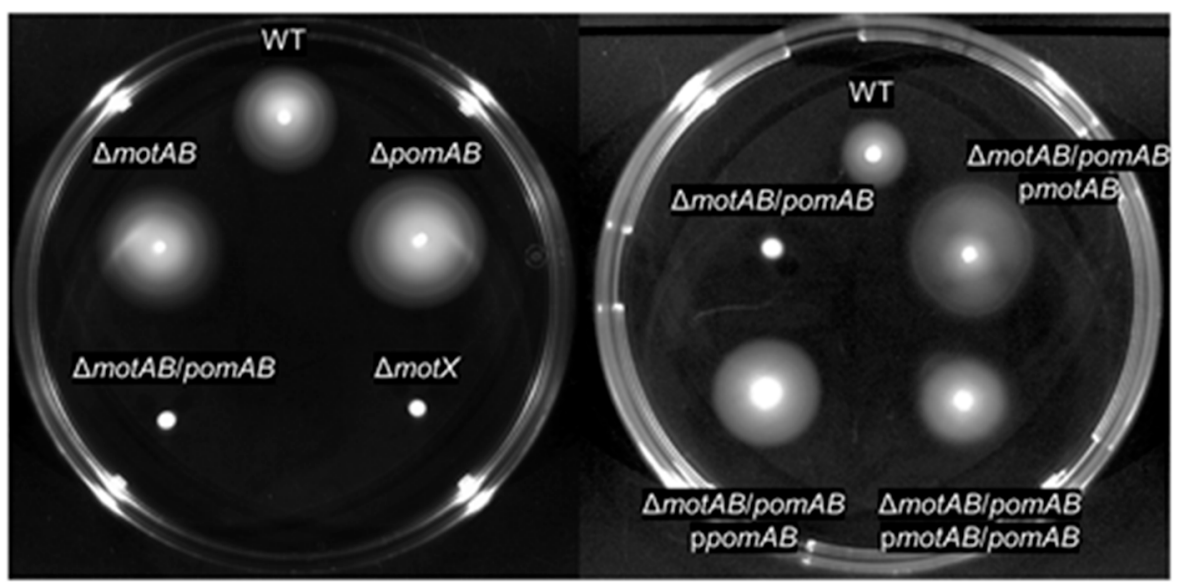

Figure 1. Motility phenotypes on the soft-agar plate. Bacteria were inoculated on LB plates containing $0.25 \%$ agar. Plates were incubated at $37^{\circ} \mathrm{C}$ and observed at $24 \mathrm{~h}$ post-inoculation.

We investigated the effect of motility on cytotoxicity and pathogenicity of A. hydrophila. LDH release assay revealed no significant difference in cytotoxicity against HeLa cells between all mutants and WT. This result showed that the loss of motor stators and motility does not affect the in vitro cytotoxicity (Figure 2A). Next, $10^{7} \mathrm{CFU}$ of $A$. hydrophila RIMD111065 WT, $\triangle$ mot $A B, \triangle p o m A B$, and $\triangle m o t A B / p o m A B$ were subcutaneously inoculated into mice. Careful observation showed that mice infected with the WT, $\triangle \operatorname{mot} A B$, and $\triangle$ pom $A B$ had extensive hair loss, swelling, and lesions (Figure 2B). On the other hand, the mice infected with the non-motile strain $\triangle m o t A B / p o m A B$ showed very localized hair loss and lesions (Figure 2B). These findings suggest that the extent of pathogenesis in soft tissue is determined by the motility of $A$. hydrophila.

To evaluate severity of the soft tissue lesions, we performed histopathological analysis and serum biochemical tests of CK, AST, and LDH. Eosin-stained fascia and muscle were clearly observed in the thighs of PBS-inoculated mice by Hematoxylin-eosin stain (Figure $3 \mathrm{~A})$. However, fascia and muscles were collapsed and indistinct staining with eosin in the thighs of mice infected with WT and $\triangle \operatorname{mot} A B / \operatorname{pom} A B$ (Figure 3A). The levels of all enzymes CK, AST, and LDH in mice infected with WT were higher than those in mice infected with non-motile strain $\triangle m o t A B / p o m A B$ (Figure 3B). The levels of AST and LDH in mice infected with $\triangle$ mot $A B /$ pom $A B$ were higher than those in mice inoculated with PBS (Figure $3 \mathrm{~B}$ ). These results demonstrated that the motility contributes to the severity and rapid spread of soft tissue lesions during the $A$. hydrophila infection.

A. hydrophila rapidly proliferates in mammalian hosts and then causes fulminant diseases such as NF and bacteremia within a short time period [7-10,13,14]. To determine the effect of motility on the proliferation of $A$. hydrophila in a murine wound infection model, we collected bacteria from muscles and spleen at $6 \mathrm{~h}$ and $12 \mathrm{~h}$ after infection with A. hydrophila RIMD111065 WT and non-motile strain $\triangle m o t A B / p o m A B$. The number of bacteria collected from the muscle of mice infected with WT was increased from $6 \mathrm{~h}$ to $12 \mathrm{~h}$ (Figure 3A). Similarly, $\triangle$ mot $A B /$ pom $A B$ were detected from the muscle at $6 \mathrm{~h}$ post-infection, and the number of bacteria was increased at $12 \mathrm{~h}$ post-infection (Figure $3 \mathrm{~A}$ ). In infection with both strains, the bacteria were detected from the spleen at $6 \mathrm{~h}$ post-infection, and there was no increase in the number of bacteria detected from the spleen at $12 \mathrm{~h}$ post-infection (Figure 3B). These results indicate that $A$. hydrophila RIMD111065 is not dependent on its motility to achieve proliferation at the local infection site and invasion of the systemic circulation resulting in bacteremia. 

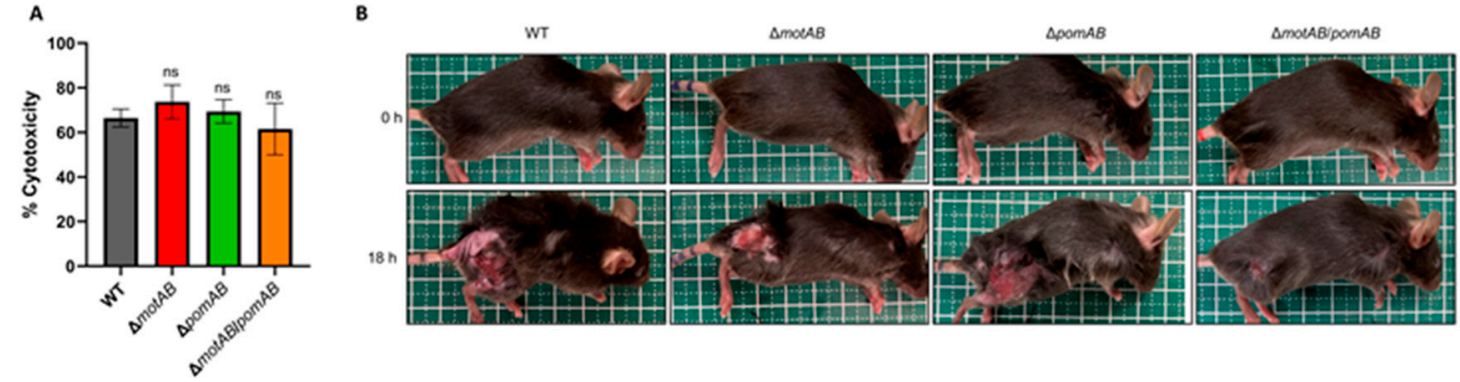

Figure 2. Soft tissue lesions in the A. hydrophila wound infection model. (A) Cytotoxicities against HeLa cells $(n=6 /$ group, $\mathrm{MOI}=10$ ) were determined by measuring the activity of LDH released from damaged cells at $2 \mathrm{~h}$ post-infection. Error bars indicate SEM. ns, not significant $(p>0.05)$ compared with WT; Mann-Whitney $U$-test. (B) Mice were s.c.-inoculated with $\mathrm{WT}, \triangle \operatorname{mot} A B, \triangle \operatorname{pom} A B$, and $\triangle \operatorname{mot} A B / \operatorname{pom} A B$. Pictures show infected mice at $0 \mathrm{~h}$ and $18 \mathrm{~h}$ post-infection.

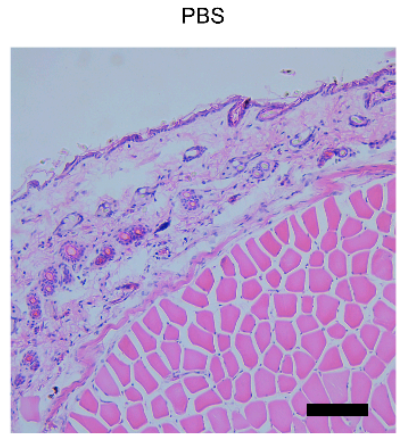

B

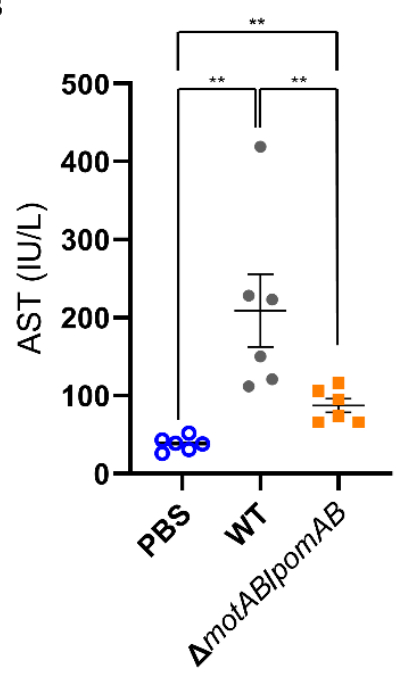

WT

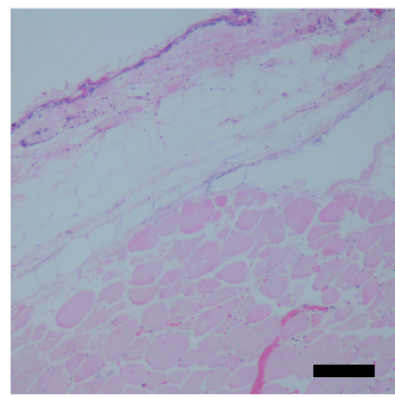

$\triangle$ motAB/pomAB

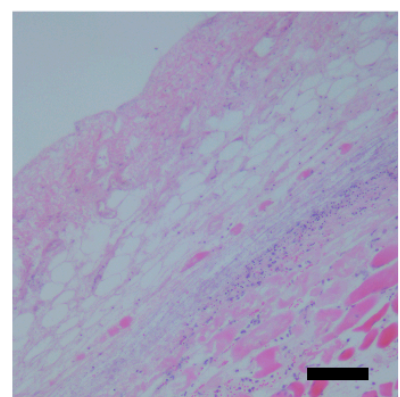

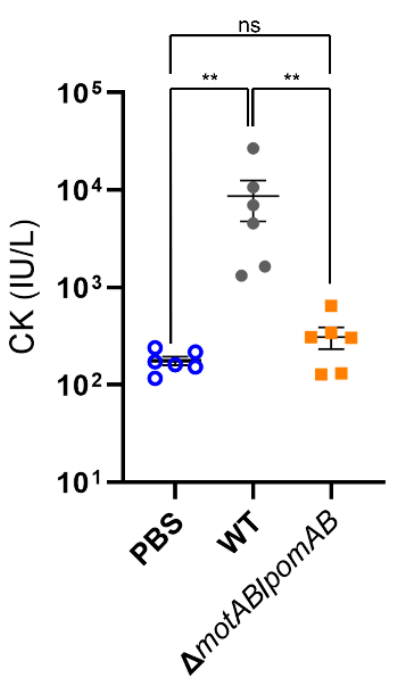

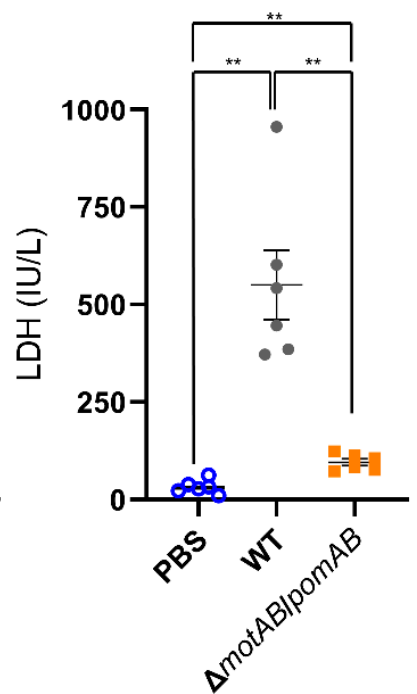

Figure 3. Mice were s.c.-inoculated with PBS, WT, and $\triangle m o t A B / p o m A B$. (A) Right caudal thighs were collected from mice at $12 \mathrm{~h}$ post-inoculation and stained with Hematoxylineosin. Scale bars, $10 \mu \mathrm{m}$. (B) The levels of AST, CK, and LDH in the sera of mice were measured at $9 \mathrm{~h}$ post-infection. Each symbol represents an individual mouse ( $n=6 /$ group). Error bars indicate SEM. ns, not significant $(p>0.05),{ }^{* *}, p<0.01$; Mann-Whitney $U$-test.

To determine the motility-dependent lethality in the murine model, we performed a survival curve analysis for mice infected with WT and non-motile strain $\triangle$ mot $A B /$ pom $A B$. All mice s.c.-inoculated with $10^{7} \mathrm{CFU}$ of WT died (Figure 4). The mice s.c.-inoculated with $\triangle m o t A B /$ pom $A B$ also died, but their survival time was significantly prolonged (Figure 4). Taken together, the motility of $A$. hydrophila is essential for progression to a fatal condition within a short time in mammalian hosts. 
A

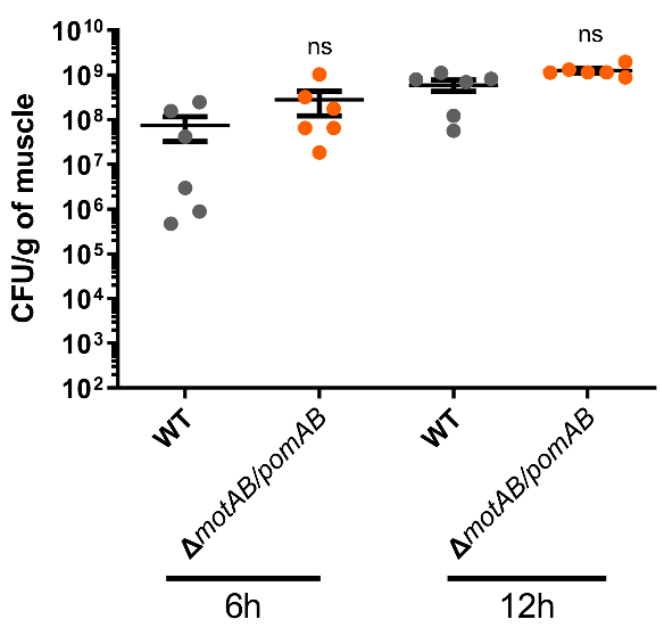

B

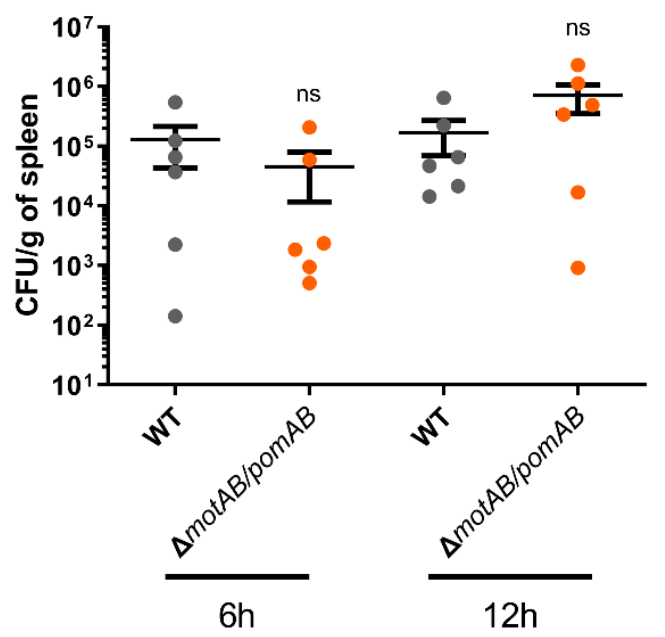

Figure 4. Bacterial proliferation in the host independent from motility. Bacterial burdens in the muscle tissue (A) and spleen (B) of mice s.c.-inoculated with WT and $\triangle \operatorname{mot} A B / p o m A B$ calculated as CFU/g at $6 \mathrm{~h}$ and $12 \mathrm{~h}$ post-infection. Each symbol represents an individual mouse ( $n=6$ /group). Error bars indicate SEM. ns, not significant $(p>0.05)$ compared with WT; Mann-Whitney $U$-test.

\section{Discussion}

NF caused by $A$. hydrophila progresses rapidly within a short time period [7-10]. This makes it difficult to treat patients and leads to significant sequelae or fatal outcomes. However, there are few studies on the mechanisms for the rapid expansion of necrotic lesions. In our wound infection model, the necrotic lesions caused by WT expanded rapidly, but the necrotic lesions caused by the non-motile strain were very localized (Figures $2 \mathrm{~B}$ and 3A). This study showed here for the first time that the motility of A. hydrophila is a crucial virulence factor associated with rapid expansion of necrotic lesions.

Most cases of $A$. hydrophila infections are known as a polymicrobial or mixed infection with different strains of $A$. hydrophila (same species) and other bacterial pathogens, such as Campylobacter, Salmonella, and Staphylococcus aureus [1,2,9-11]. The infections frequently become severe in immunocompromised hosts such as liver disease [1,2,9]. However, RIMD111065 showed pathogenicity and lethality in healthy mice by monomicrobial infection (Figure 2B, Figure 3 and Figure 5). These results indicated that this strain has a mechanism to evade the immune system at the site of infection or in the internal organs of a healthy host, not depending on other pathogens. Additionally, since the non-motile strain was detected from the local infection site and the spleen similar to the WT, this study showed that the evasion mechanism does not depend on the bacterial motility.

A. hydrophila is a motile pathogen known to be distributed in various aquatic environments and infects a wide variety of hosts, including fish and mammals [1-8]. Motility is generally affected by the secretion of toxins, the quorum-sensing system, and/or the environment $[4,7,8,16-19,36-38]$. As an example of how toxin secretion affects motility, Ponnusamy et al. showed that the motility of $A$. hydrophila was significantly increased when exoA was deleted [7]. Quorum sensing is necessary for efficient proliferation both in the environment and in the host and may switch between motile state and non-motile state, depending on the bacterial density $[37,38]$. Kozlova et al. showed that quorum-sensing mutations in A. hydrophila reduce motility [37]. Jahid et al. showed that differences in salt concentration in the environment affect quorum-sensing and motility [4]. They also showed that $A$. hydrophila proliferates and is motile in a wide range of salt concentrations from $0 \%$ to $3 \%$ [4]. This adaptability is thought to be due to the two types of motor stator possessed by $A$. hydrophila as shown in this study. We also demonstrated that $A$. hydrophila has mutually complementary MotAB and PomAB (Figure 1). Flagellar systems with the 
two types of stators have only been found in a few bacteria such as $S$. oneidensis and $V$. alginolyticus $[25,32,33]$. The adaptability of $A$. hydrophila contributes to the proliferation and the pathogenicity in the host.

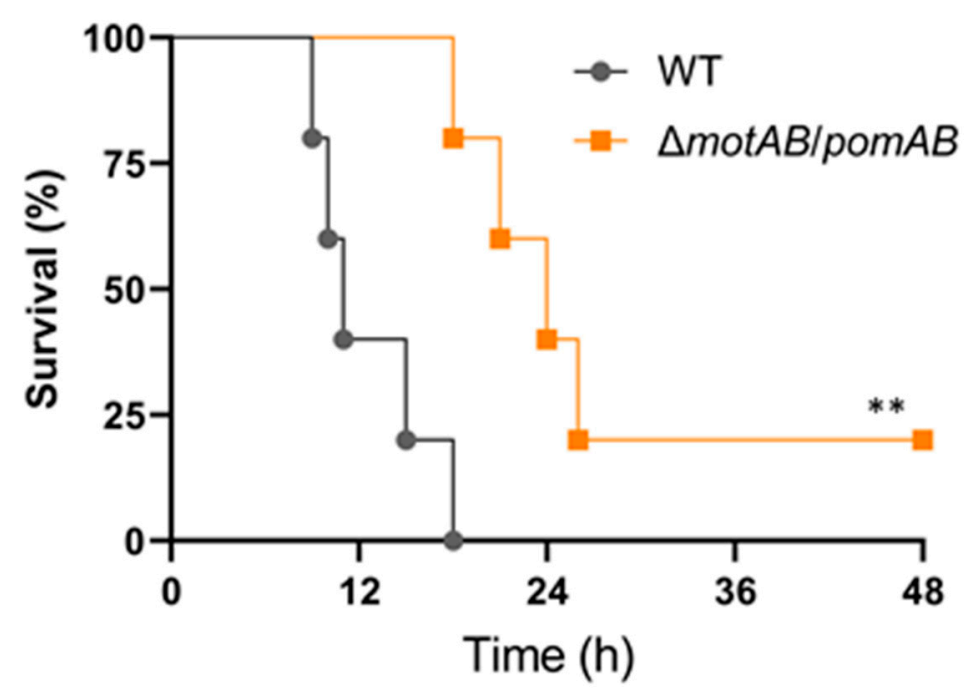

Figure 5. Motility-dependent lethality in the A. hydrophila infection model. Kaplan-Meier survival curves for mice inoculated s.c. with WT and $\triangle \operatorname{mot} A B /$ pom $A B$ and monitored for $72 \mathrm{~h}$. Each symbol represents an individual mouse $\left(n=6\right.$ /group). ${ }^{* *}, p<0.01$; log-rank test.

Various toxins are involved in the pathogenicity of A. hydrophila infection [5-8]. All strains used in this study caused cytotoxicity (Figure 2A). This result showed that defects in the two types of stators did not affect toxin secretion for cytotoxicity. Aerolysin is well known cytotoxic enterotoxin of $A$. hydrophila [8,39-41]. It is secreted by the type II secretion system and also known to affect lethality in mice, although its role in wound infection is unknown. RIMD111065 has a gene encoding Aerolysin, and this toxin may contribute to the cytotoxicity and lethality. A toxin ExoA is reported as a crucial virulence factor involved in the onset of the NF in A. hydrophila infection [7,11]. However, RIMD111065 does not have a gene encoding ExoA. The present study revealed that this strain caused necrotic lesions (Figures 2B and 3A). These facts strongly suggest that RIMD111065 may have a novel necrosis factor not dependent on ExoA. In addition, its motility contributed to aggravation. Thus, the necrosis-related factors will function only in the local site where the $A$. hydrophila proliferates after spreading through soft tissues by its motility.

The effects of motility on bacterial pathogenicity have been reported in a study on Vibrio vulnificus wound infection $[31,42,43]$. Vibrio vulnificus is also one of the causative agents of NSTI, and clinical syndromes resulting from infection with $A$. hydrophila resemble those due to Vibrio vulnificus. A motility-deficient mutant of V. vulnificus had reduced proliferation ability and pathogenicity at the site of infection [31]. However, the proliferation ability of $A$. hydrophila was not affected by lack of motility as shown in this study. $V$. vulnificus requires motility to expand necrosis from the superficial layer to the deep layer in the muscle, while $A$. hydrophila required motility to expand necrosis in the skin. These findings provide useful evidence that the motility-dependent pathogenic mechanisms of $A$. hydrophila and $V$. vulnificus have an effect on clinical symptoms.

Our results also indicate that $A$. hydrophila has an ability to invade the systemic circulation and then proliferate independent of motility. Romero et al. reported that non-motile $A$. hydrophila AH-1:: motX can proliferate without motility in models of fish and intraperitoneally infected mice [6]. Their analysis with strain lacking polar flagella showed that $A$. hydrophila require flagellar-based adhesion to proliferate in the circulation. In addition, our study shows that the extent of necrosis based of flagellar motility influences the survival time of mice. This is the first study to report motility as one of the critical factors for the evolution of $A$. hydrophila NSTI. 
Supplementary Materials: The following are available online at https:/ /www.mdpi.com/2076-260 7/9/1/10/s1, Figure S1: Protein sequence of MotA were aligned by manually PRALINE program, Figure S2: Protein sequence of MotB were aligned by manually PRALINE program, Figure S3: Protein sequence of PomA were aligned by manually PRALINE program, Figure S4: Protein sequence of PomB were aligned by manually PRALINE program.

Author Contributions: Conceptualization: K.Y. and T.K.; methodology: K.Y. and Y.A.; validation: K.Y., A.N., M.Y., M.N., and Y.A.; formal analysis: K.Y.; investigation: K.Y.; data duration: K.Y.; writing—original draft preparation: K.Y.; writing—review and editing: T.K.; software: Y.A.; supervision: S.U.; project administration: K.Y.; funding acquisition: K.Y. All authors have read and agreed to the published version of the manuscript.

Funding: This work was supported by the Japan Society for the Promotion of Science KAKENHI under Grant number 19K15979; Kitasato University Research Grant for Young Researchers under Grant number 3250. The founder had no role in study design, data collection, and interpretation, or the decision to submit the work for publication. The authors have no additional financial interests.

Institutional Review Board Statement: All animal studies were carried out in strict accordance with the Guidelines for Animal Experimentation of the Japanese Association for Laboratory Animal Science (JALAS). The animal experimentation protocol was approved by the president of Kitasato University based on the judgment of the Institutional Animal Care and Use Committee of Kitasato University on July 14, 2020 (Approval No. 19-220).

Informed Consent Statement: Not applicable.

Data Availability Statement: Sequence data that support the findings of this study have been deposited in DDBJ Sequence Database and DRA (https://www.ddbj.nig.ac.jp/index.html). Accession numbers are available in Materials and Methods. The complete genome sequence for A. hydrophila RIMD111065 can be found under bioproject ID PRJDB10897, specifically, complete chromosome (GenBank accession: AP024234).

Conflicts of Interest: The authors declare no conflict of interest.

\section{References}

1. Fernández-Bravo, A.; Figueras, M.J. An update on the genus Aeromonas: Taxonomy, epidemiology, and pathogenicity. Microorganisms 2020, 8, 129. [CrossRef]

2. Janda, J.M.; Abbott, S.L. The genus Aeromonas: Taxonomy, pathogenicity, and infection. Clin. Microbiol. Rev. 2010, 23, 35-73. [CrossRef]

3. Parker, J.L.; Shaw, J.G. Aeromonas spp. clinical microbiology and disease. J. Infect. 2011, 62, 109-118. [CrossRef]

4. Jahid, I.K.; Mizan, M.F.R.; Ha, A.J.; Ha, S.-D. Effect of salinity and incubation time of planktonic cells on biofilm formation, motility, exoprotease production, and quorum sensing of Aeromonas hydrophila. Food Microbiol. 2015, 49, 142-151. [CrossRef]

5. Tomás, J.M. The main Aeromonas pathogenic factors. ISRN Microbiol. 2012, 256261. [CrossRef]

6. Romero, A.; Saraceni, P.R.; Merino, S.; Figueras, A.; Tomás, J.M.; Novoa, B. The animal model determines the results of Aeromonas virulence factors. Front. Microbiol. 2016, 7. [CrossRef] [PubMed]

7. Ponnusamy, D.; Kozlova, E.V.; Sha, J.; Erova, T.E.; Azar, S.R.; Fitts, E.C.; Kirtley, M.L.; Tiner, B.L.; Andersson, J.A.; Grim, C.J.; et al. Cross-talk among flesh-eating Aeromonas hydrophila strains in mixed infection leading to necrotizing fasciitis. Proc. Natl. Acad. Sci. USA 2016, 113, 722. [CrossRef] [PubMed]

8. Grim, C.J.; Kozlova, E.V.; Ponnusamy, D.; Fitts, E.C.; Sha, J.; Kirtley, M.L.; van Lier, C.J.; Tiner, B.L.; Erova, T.E.; Joseph, S.J.; et al. Functional genomic characterization of virulence factors from necrotizing fasciitis-causing strains of Aeromonas hydrophila. Appl. Environ. Microbiol. 2014, 80, 4162-4183. [CrossRef] [PubMed]

9. Huang, T.-Y.; Peng, K.-T.; Hsu, W.-H.; Hung, C.-H.; Chuang, F.-Y.; Tsai, Y.-H. Independent Predictors of Mortality for Aeromonas Necrotizing Fasciitis of Limbs: An 18-year Retrospective Study. Sci. Rep. 2020, 10, 7716. [CrossRef] [PubMed]

10. Lamy, B.; Kodjo, A.; colBVH Study Group; Laurent, F. Prospective Nationwide Study of Aeromonas Infections in France. J. Clin. Microbiol. 2009, 47, 1234-1237. [CrossRef]

11. Hiransuthikul, N.; Tantisiriwat, W.; Lertutsahakul, K.; Vibhagool, A.; Boonma, P. Skin and Soft-Tissue Infections among Tsunami Survivors in Southern Thailand. Clin. Infect. Dis 2005, 41, e93-e96. [CrossRef] [PubMed]

12. Presley, S.M.; Rainwater, T.R.; Austin, G.P.; Platt, S.G.; Zak, J.C.; Cobb, G.P.; Marsland, E.J.; Tian, K.; Zhang, B.; Anderson, T.A.; et al. Assessment of Pathogens and Toxicants in New Orleans, LA Following Hurricane Katrina. Environ. Sci. Technol. 2006, 40, 468-474. [CrossRef] [PubMed]

13. Hakkarainen, T.W.; Kopari, N.M.; Pham, T.N.; Evans, H.L. Necrotizing soft tissue infections: Review and current concepts in treatment, systems of care, and outcomes. Curr. Probl. Surg. 2014, 51, 344-362. [CrossRef] [PubMed]

14. Stevens, D.L.; Bryant, A.E. Necrotizing soft-tissue infections. N Engl. J. Med. 2017, 377, 2253-2265. [CrossRef] [PubMed] 
15. Fernández-Bravo, A.; Kilgore, P.B.; Andersson, J.A.; Blears, E.; Figueras, M.J.; Hasan, N.A.; Colwell, R.R.; Sha, J.; Chopra, A.K. T6SS and ExoA of flesh-eating Aeromonas hydrophila in peritonitis and necrotizing fasciitis during mono- and polymicrobial infections. Proc. Natl. Acad. Sci. USA 2019, 116, 24084-24092. [CrossRef]

16. Terashima, H.; Kojima, S.; Homma, M. Chapter 2 Flagellar Motility in Bacteria: Structure and Function of Flagellar Motor. Int. Rev. Cell Mol. Biol. 2008, 270, 39-85.

17. Berg, H.C. The rotary motor of bacterial flagella. Annu. Rev. Biochem. 2003, 72, 19-54. [CrossRef]

18. Minamino, T.; Imada, K.; Namba, K. Molecular motors of the bacterial flagella. Curr. Opin. Struct. Biol. 2008, 18, 693-701. [CrossRef]

19. Nakamura, S.; Minamino, T. Flagella-driven motility of bacteria. Biomolecules 2019, 9. [CrossRef]

20. Josenhans, C.; Suerbaum, S. The role of motility as a virulence factor in bacteria. Int. J. Med. Microbiol. 2002, 291, 605-614. [CrossRef]

21. Hayashi, F.; Smith, K.D.; Ozinsky, A.; Hawn, T.R.; Yi, E.C.; Goodlett, D.R.; Eng, J.K.; Akira, S.; Underhill, D.M.; Aderem, A The innate immune response to bacterial flagellin is mediated by Toll-like receptor 5. Nature 2001, 410, 1099-1103. [CrossRef] [PubMed]

22. Kirov, S.M.; Castrisios, M.; Shaw, J.G. Aeromonas flagella (polar and lateral) are enterocyte adhesins that contribute to biofilm formation on surfaces. Infect. Immun. 2004, 72, 1939-1945. [CrossRef] [PubMed]

23. Merino, S.; Rubires, X.; Aguilar, A.; Tomás, J.M. The role of flagella and motility in the adherence and invasion to fish cell lines by Aeromonas hydrophila serogroup O:34 strains. FEMS Microbiol Lett 1997, 151, 213-217. [CrossRef] [PubMed]

24. Nishihara, Y.; Kitao, A. Gate-controlled proton diffusion and protonation-induced ratchet motion in the stator of the bacterial flagellar motor. Proc. Natl. Acad. Sci. USA 2015. [CrossRef]

25. Yorimitsu, T.; Sato, K.; Asai, Y.; Kawagishi, I.; Homma, M. Functional Interaction between PomA and PomB, the Na+-driven flagellar motor components of Vibrio alginolyticus. J. Bacteriol. 1999, 181, 5103-5106. [CrossRef]

26. Yorimitsu, T.; Homma, M. Na+-driven flagellar motor of Vibrio. Biochim. Biophys. Acta BBA Bioenerg. 2001, 1505, 82-93. [CrossRef]

27. Yorimitsu, T.; Sowa, Y.; Ishijima, A.; Yakushi, T.; Homma, M. The systematic substitutions around the conserved charged residues of the cytoplasmic loop of Na+-driven flagellar motor component PomA. J. Mol. Biol. 2002, 320, 403-413. [CrossRef]

28. Fukuoka, H.; Yakushi, T.; Homma, M. Concerted effects of amino acid substitutions in conserved charged residues and other residues in the cytoplasmic domain of PomA, a stator component of Na+-driven flagella. J. Bacteriol. 2004, 186, 6749-6758. [CrossRef]

29. Wilhelms, M.; Vilches, S.; Molero, R.; Shaw, J.G.; Tomás, J.M.; Merino, S. Two redundant sodium-driven stator motor proteins are involved in Aeromonas hydrophila polar flagellum rotation. J. Bacteriol. 2009, 191, 2206-2217. [CrossRef]

30. Simossis, V.A.; Heringa, J. PRALINE: A multiple sequence alignment toolbox that integrates homology-extended and secondary structure information. Nucleic Acids Res. 2005, 33, W289-W294. [CrossRef]

31. Yamazaki, K.; Kashimoto, T.; Kado, T.; Akeda, Y.; Yoshioka, K.; Kodama, T.; Yamamoto, M.; Okamura, M.; Kakuda, T.; Ueno, S. Chemotactic invasion in deep soft tissue by Vibrio vulnificus is essential for the progression of necrotic lesions. Virulence 2020, 11, 840-848. [CrossRef] [PubMed]

32. Paulick, A.; Delalez, N.J.; Brenzinger, S.; Steel, B.C.; Berry, R.M.; Armitage, J.P.; Thormann, K.M. Dual stator dynamics in the Shewanella oneidensis MR-1 flagellar motor. Mol. Microbiol. 2015, 96, 993-1001. [CrossRef] [PubMed]

33. Paulick, A.; Koerdt, A.; Lassak, J.; Huntley, S.; Wilms, I.; Narberhaus, F.; Thormann, K.M. Two different stator systems drive a single polar flagellum in Shewanella oneidensis MR-1. Mol. Microbiol. 2009, 71, 836-850. [CrossRef] [PubMed]

34. Terauchi, T.; Terashima, H.; Kojima, S.; Homma, M. A conserved residue, PomB-F22, in the transmembrane segment of the flagellar stator complex, has a critical role in conducting ions and generating torque. Microbiol. Res. 2011, 157, $2422-2432$. [CrossRef] [PubMed]

35. Molero, R.; Wilhelms, M.; Infanzón, B.; Tomás, J.M.; Merino, S. Aeromonas hydrophila motY is essential for polar flagellum function, and requires coordinate expression of motX and Pom proteins. Microbiology 2011, 157, 2772-2784. [CrossRef] [PubMed]

36. Lynch, M.J.; Swift, S.; Kirke, D.F.; Keevil, C.W.; Dodd, C.E.R.; Williams, P. The regulation of biofilm development by quorum sensing in Aeromonas hydrophila. Environ. Microbiol. 2002, 4, 18-28. [CrossRef]

37. Kozlova, E.V.; Khajanchi, B.K.; Sha, J.; Chopra, A.K. Quorum sensing and c-di-GMP-dependent alterations in gene transcripts and virulence-associated phenotypes in a clinical isolate of Aeromonas hydrophila. Microb. Pathog. 2011, 50, 213-223. [CrossRef]

38. Minamino, T.; Terahara, N.; Kojima, S.; Namba, K. Autonomous control mechanism of stator assembly in the bacterial flagellar motor in response to changes in the environment. Mol. Microbiol. 2018, 109, 723-734. [CrossRef]

39. Chakraborty, T.; Huhle, B.; Hof, H.; Bergbauer, H.; Goebel, W. Marker exchange mutagenesis of the aerolysin determinant in Aeromonas hydrophila demonstrates the role of aerolysin in A. hydrophila-associated systemic infections. Infect. Immun. 1987, 55, 2274-2280. [CrossRef]

40. Chopra, A.K.; Xu, X.-J.; Ribardo, D.; Gonzalez, M.; Kuhl, K.; Peterson, J.W.; Houston, C.W. The Cytotoxic enterotoxin of Aeromonas hydrophila induces proinflammatory cytokine production and activates arachidonic acid metabolism in macrophages. Infect. Immun. 2000, 68, 2808-2818. [CrossRef]

41. Fadl, A.A.; Galindo, C.L.; Sha, J.; Erova, T.E.; Houston, C.W.; Olano, J.P.; Chopra, A.K. Deletion of the genes encoding the type III secretion system and cytotoxic enterotoxin alters host responses to Aeromonas hydrophila infection. Microb. Pathog. 2006, 40, 198-210. [CrossRef] [PubMed] 
42. Oliver, J.D. The biology of Vibrio vulnificus. Microbiol. Spectr. 2015, 3. [CrossRef] [PubMed]

43. Yamazaki, K.; Kashimoto, T.; Morita, M.; Kado, T.; Matsuda, K.; Yamasaki, M.; Ueno, S. identification of in vivo essential genes of Vibrio vulnificus for establishment of wound infection by Signature-tagged mutagenesis. Front. Microbiol. 2019, 10. [CrossRef] [PubMed] 